\title{
A hybrid multi criteria decision analysis for engineering project manager evaluation
}

\author{
Nguyen Le Hoang Thuy To Quyen ${ }^{1}$, Phong Thanh Nguyen ${ }^{1,2, *}$, Vy Dang Bich Huynh ${ }^{1}$ \\ ${ }^{1}$ Ho Chi Minh City Open University (HCMCOU), Ho Chi Minh City, Vietnam \\ ${ }^{2}$ CEM Division, Chulalongkorn University (CU), Bangkok, Thailand
}

\section{A R T I C L E I N F O}

\section{Article history:}

Received 31 December 2016

Received in revised form

6 March 2017

Accepted 7 March 2017

\section{Keywords:}

Decision analysis

Analytic hierarchy process

TOPSIS

Project manager

\section{Introduction}

It is a challenged decision-making process for any organization to select an eligible candidate for a management position because his or her actions significantly impact on its achievements (Gatewood et al., 2015). Also, if unqualified people are chosen for a management position, this may discourage other personnel who are more qualified and appropriate for the position. Furthermore, their motivation to work and devote to the company shall be eliminated. Especially, in large-scale enterprises, the demand for the engineering projects implementation within the enterprise is inevitable (Bagherinia and Olapour, 2016; Nguyen et al., 2017a). In those organizations, projects are typically associated with a tremendous amount of investment capital as well as time, quality, and budget constraints (Ullah et al., 2016). A key success factor of their projects is a project manager (Mohammadi et al., 2014; Sadeghi et al., 2014).

Project manager plays an extremely significant role in the success of projects. The project manager must be able to organize and operate their projects by using their knowledge, experience, and necessary personal skills to achieve all project objectives (ElSabaa, 2001; Odusami, 2002). The selection of

\footnotetext{
* Corresponding Author.

Email Address: ntphong1711@gmail.com (P. T. Nguyen) https://doi.org/10.21833/ijaas.2017.04.008

2313-626X/C 2017 The Authors. Published by IASE.

This is an open access article under the CC BY-NC-ND license

(http://creativecommons.org/licenses/by-nc-nd/4.0/)
}

qualified project managers is a challenging problem for any firms. Normally, it depends on company's specific objectives, the availability of human resources and the preferences of decision makers (Nguyen et al., 2017b). Yet, the previous studies on project manager selection models have been very limited. Most of the existing evaluating and decisionmaking models are usually based on subjective opinions of decision makers, resulting in irrational and inappropriate decisions (Behzadian et al., 2012; Tran, 2016). In addition, the models also ignore the factors concerning uncertainty and the importance of assessors (Babaee Asil and Fanati Rashidi, 2015; Vavan and Braike, 2015). To overcome these disadvantages, we propose a quantitative model for project manager selection by using the AHP and TOPSIS method.

\section{Research background}

The first step to building the selection project manager model is to identify key selection criteria. Typically, different researchers and companies have different sets of selection criteria. For example, Pinto (2015) ranked the nine most critical skills of effective project managers in order of decreased importance including leader competencies, visionary, technically competent, decisive, communication skills, motivator skills, stands up to top management when necessary, supports project members and encourages new ideas. Similarly, Meredith and Mantel (2011) summarized the essential requirements and skills of a project 
manager into six groups including communication skills, technical background skills, team skills, coping skills, organization skills and leadership skills. In more detail, Rashidi et al. (2010) pointed out twenty-three selection criteria and divided into four groups: technical and professional background, educational background, demographic features and general management abilities. Mohammadi et al. (2014) suggested eighteen selection criteria in evaluating project manager applicants, including job experience, academic achievement, communication skills, Microsoft project software, planning skill, organizing skill, leading skill, controlling and monitoring skill, conducting meetings, record keeping, time management, property management, worker welfare management, rules and regulation, problem solving skills, decision analysis, multitasking, and correspondence. However, Goodwin (1993), Pheng and Chuan (2006) proved that conceptual skills, human skills, and technical expertise are the main basic requirements. Despite different viewpoints of different researchers, in general, there are many similar criteria in assessing the project manager. Also, the selection criteria will depend on the project's characteristics and scale as well as the organization's objectives and vision.

In this research, we identified engineering project manager selection criteria using in-depth interviews with seventy-two experts in Vietnam companies. The results showed that there are eighteen criteria divided into four main groups in the selection process as summarized in Table 1.

Table 1: Project manager selection criteria

\section{Basic requirements}

Experience managing and operating similar projects Project management academic background Knowledge of law and regulation English languages and IT capability Physical and mental health Project management skills Planning skills Organizing skills Leading skills Controlling and monitoring skills Administration skills

Conducting meetings skills Negotiations skills

Human resources management skills Time management skills Personal skills Communication skills Decision-making skills Problem-solving skills Teamwork skills Training skills

\section{Research methodology}

\subsection{AHP}

The Analytic Hierarchy Process (AHP), introduced by Saaty (2005) was known as a multicriteria decision analysis method. It is widely applied in outstanding works of various fields relating to best option selection, conflict solution, resource allocation and optimization of the decision-making process (Nguyen et al., 2016). In this study, the AHP is employed to establish weights for project manager evaluation criteria in the hierarchical model.

Step 1. Hierarchy Construction: Hierarchy is established by breaking down the overall goal into basic elements. The review of literature and authors' critical judgments has led to the suggestion of the hierarchical model including four levels and eighteen sub-levels of project manager indicators.

Step 2. The performance of in-depth interviews with experts based on pairwise comparison matrix. In this step, the relative importance of each element at its level is evaluated. The philosophy of weights calculation behind the AHP is to compare pairwise with a scale of 1-9 as indicated in Table 2.

Table 2: The fundamental Saaty (2005) scale of 1-9

\begin{tabular}{cc}
\hline Scale & Description \\
\hline 1 & Two activities are equally important to the goal \\
2 & One activity are equally to moderately important to the goal \\
3 & One activity is moderately favoured to another \\
4 & One activity is moderately to strongly favoured to another \\
5 & One activity is strongly favoured to another \\
6 & One activity is strongly to very strongly favoured to another \\
7 & One activity is very strongly favoured to another \\
8 & One activity is very to extremely strongly favoured to \\
9 & another \\
\hline
\end{tabular}

Step 3. Estimation of priority vector for every factor and evaluation of consistency ratio (CR) of experts' judgments.

The factor's priorities are acquired by averaging the row values of the normalized matrix. In practical problems, we are not always able to establish the bridging relation in pairwise comparisons. For example, alternative A may be at a higher rank than alternative $B$; alternative $B$ may be superior to alternative $C$, but this does not always mean that $A$ is a better option than $C$. This shows the realistic characteristic of practical problems which is called inconsistency. Inconsistency is real, but its value should not be too high. Otherwise, the evaluation is not accurate. The consistency ratio is used to assess the inconsistency of each level. If it is equal or lower than 0.1, it means that the decision maker's evaluation is relatively consistent. Otherwise, reevaluation of appropriate level should be carried out. The consistency ratio (CR) was calculated as a ratio of consistency index (CI) divided by random index (RI). Table 3 presents the random consistency index.

Step 4. Sensitivity analysis: A study of how changes in the weights of the criteria could affect the result is done to understand the rationale behind the obtained results. Based on the synthesis results and sensitivity analysis, a decision can be made.

\subsection{TOPSIS}

In this research, the proposed TOPSIS procedure to rank project manager candidate is conducted with the following steps (Ju and Wang, 2012; Önüt et al., 2010): 
Step one. Develop the normalized decision matrix of $n$ candidates on $m$ criteria by using distributive normalization (Eq. 1):

$r_{i j}=\frac{x_{i j}}{\sqrt{\sum_{j=1}^{n} x_{i j}^{2}}}$

where, $r_{i j}$ stands for the normalized value; $i=1,2,3, \ldots$, $m$ and $j=1,2,3, \ldots, n$.

Step two. Calculate the weighted normalized decision matrix (Eq. 2).

$v_{i j}=w_{j}{ }^{*} r_{i j}$

where, $w_{\mathrm{i}}$ stands for the weight of the individual criterion; $i=1, \ldots, m$ and $j=1,2, \ldots, n$.

Step three. Identify the positive ideal solution and the negative one. For the positive ideal solution (Eq. 3):

$V^{+}=\left(v_{1}^{+}, \ldots, v_{j}^{+}, \ldots, v_{n}^{+}\right)$

and for the negative ideal solution (Eq. 4):

$V^{-}=\left(v_{1}^{-}, \ldots, v_{j}^{-}, \ldots, v_{n}^{-}\right)$

where, $v_{j}^{-}=\min _{i}\left(v_{i j}\right)$ if $C_{j}$ is to be minimized and $v_{j}^{+}=\max _{i}\left(v_{i j}\right)$ if $C_{j}$ is to be maximized.

Step four. Calculate the distance for each alternative to both the positive ideal solution point (Eq. 5):

$d_{i}^{+}=\sqrt{\sum_{j=1}^{n}\left(v_{j}^{+}-v_{i j}\right)^{2}}$

and the negative ideal one (Eq. 6):

$d_{i}^{-}=\sqrt{\sum_{j=1}^{n}\left(v_{j}^{-}-v_{i j}\right)^{2}}$

where, $i=1,2, \ldots, m ; v_{j}^{+}=\max _{i}\left(v_{i j}\right)$ and $v_{j}^{-}=$ $\min _{i}\left(v_{i j}\right)$.

Step five. Calculate each alternative's relative closeness coefficient to the ideal solution (Eq. 7):

$C C_{i}=\frac{d_{i}^{-}}{d_{i}^{+}+d_{i}^{-}}$

Step six. Order the alternatives and choose the one with a maximum value of closeness coefficients.

\section{Numerical illustration}

The effectiveness of these methods is discussed through a case study in one Construction Company in Vietnam. To be simple for illustrative purposes only, the group of decision makers considered four main criteria with their significant weights calculated by AHP methodology as presented in Table 4.

Five engineering project manager candidates were selected and evaluated for their capacity for project management position with the scores in Table 5.

Table 3: Random consistency index

\begin{tabular}{ccccccccccc}
\hline $\mathrm{n}$ & 1 & 2 & 3 & 4 & 5 & 6 & 7 & 8 & 9 & 10 \\
\hline RI & 0.00 & 0.00 & 0.58 & 0.9 & 1.12 & 1.24 & 1.32 & 1.41 & 1.45 & 1.49 \\
\hline
\end{tabular}

Table 4: Main criteria for project manager selection

\begin{tabular}{ccc}
\multicolumn{3}{c}{ problem } \\
\hline & Main criteria & Weight \\
\cline { 2 - 3 } BAR & Basic requirements & 0.42 \\
PMS & Project management skills & 0.37 \\
ADS & Administration skills & 0.12 \\
PES & Personal skills & 0.09 \\
\hline
\end{tabular}

Table 5: The evaluation scores for engineering project

\begin{tabular}{lcccc}
\multicolumn{5}{c}{ manager candidates } \\
\hline$E P M$ & BAR & PMS & ADS & PES \\
\hline$E P M_{1}$ & 85 & 70 & 70 & 60 \\
$E P M_{2}$ & 75 & 85 & 90 & 55 \\
$E P M_{3}$ & 70 & 85 & 75 & 90 \\
$E P M_{4}$ & 70 & 65 & 70 & 60 \\
$E P M_{5}$ & 75 & 80 & 70 & 85 \\
\hline
\end{tabular}

From the Table 5, we can see that the engineering project manager candidate $\mathrm{EPM}_{4}$ has the evaluation scores dominated by other candidates. Therefore, in the screening step, that alternative was removed out of further calculation based on TOPSIS method. Then evaluators assessed the remaining project manager candidates by using TOPSIS procedure. The results show that the engineering project manager candidate $\mathrm{EPM}_{2}$ is the best because it gains the highest relative closeness coefficient score (0.54) among all project manager candidates.

\section{Conclusion}

This paper proposes a quantitative approach to select a project manager by using multiple criteria decision-making techniques, namely AHP and TOPSIS. We believe that the proposed method is a very useful decision-making tool for engineering project manager selection challenges. First, this method can provide an even more structured way and reduce the time in evaluation and selection process of an engineering project manager. Compared with traditional methods such as scoring technique, AHP and TOPSIS techniques are very useful when the number of assessment criteria, as well as the number of project manager candidates, is significant. Moreover, it also takes into account the importance of the role and expertise of decisionmakers in the evaluation process.

\section{Acknowledgment}

The authors gratefully acknowledge Ho Chi Minh City Open University (HCMCOU), Vietnam and Chulalongkorn University (CU), Thailand for partial supporting this research.

\section{References}

Babaee Asil HR and Fanati Rashidi S (2015). Weight control with using goal programming in data envelopment analysis. 
International Journal of Advanced and Applied Sciences, 2(3):1-5

Bagherinia K and Olapour M (2016). Performance evaluation of project management implementation based on PMBOK-2008 standard (case study: Ahvaz Metro project). International Journal of Advanced and Applied Sciences, 3(9): 10-15

Behzadian M, Otaghsara K, Yazdani M, and Ignatius J (2012). A state-of the-art survey of TOPSIS applications. Expert Systems with Applications, 39(17): 13051-13069.

El-Sabaa S (2001). The skills and career path of an effective project manager. International Journal of Project Management, 19(1): 1-7.

Gatewood R, Field H, and Barrick M (2015). Human resource selection. Nelson Education, Scarborough, Canada.

Goodwin R (1993). Skills required of effective project managers. Journal of Management in Engineering, 9(3): 217-226.

Ju Y and Wang A (2012). Emergency alternative evaluation under group decision makers: A method of incorporating DS/AHP with extended TOPSIS. Expert Systems with Applications, 39(1): 1315-1323.

Meredith JR and Mantel SJ (2011). Project management: A managerial approach. John Wiley and Sons, NJ, USA.

Mohammadi F, Sadi K, Nateghi F, Abdullah A, and Skitmore M (2014). A hybrid quality function deployment and cybernetic analytic network process model for project manager selection. Journal of Civil Engineering and Management, 20(6): 795-809.

Nguyen PT, Nguyen TA, Ha NTH, and Nguyen TN (2017a). Facilities management in high rise buildings using building information modeling. International Journal of Advanced and Applied Sciences, 4(2): 1-9.

Nguyen PV, Nguyen PT, Nguyen QTTHL, and Huynh VBD (2016). Calculating Weights of Social Capital Index Using Analytic Hierarchy Process. International Journal of Economics and Financial Issues, 6(3): 1189-1193.

Nguyen TP, Phuc NV, and Quyen NLHTT (2017b). Application of fuzzy analytic network process and TOPSIS method for material supplier selection. In the Key Engineering Materials, Trans Tech Publications, Zurich, Switzerland, 728: 411-415.

Odusami KT (2002). Perceptions of construction professionals concerning important skills of effective project leaders. Journal of Management in Engineering, 18(2): 61-67.

Önüt S, Efendigil T, and Soner S (2010). A combined fuzzy mcdm approach for selecting shopping center site: An example from Istanbul, Turkey. Expert Systems with Applications, 37(3): 1973-1980.

Pheng LS and Chuan QT (2006). Environmental factors and work performance of project managers in the construction industry. International Journal of Project Management, 24(1): 24-37.

Pinto JK (2015). Project Management: Achieving competitive advantage. $4^{\text {th }}$ Edition, Pearson/Prentice Hall, NJ, USA.

Rashidi A, Jazebi F, and Brilakis I (2010). Neurofuzzy genetic system for selection of construction project managers. Journal of Construction Engineering and Management, 137(1): 17-29.

Saaty TL (2005). Making and validating complex decisions with the AHP/ANP. Journal of Systems Science and Systems Engineering, 14(1): 1-36.

Sadeghi H, Mousakhani M, Yazdani M, and Delavari M (2014). Evaluating project managers by an interval decision-making method based on a new project manager competency model. Arabian Journal for Science and Engineering, 39(2): 14171430.

Tran TT (2016). Evaluating and forecasting performance using past data of an industry: An analysis of electronic manufacturing services industry. International Journal of Advanced and Applied Sciences, 3(12): 5-20.

Ullah K, Abdullah A, and Nagapan S (2016). A framework for avoiding cost overruns in Malaysian construction projects. International Journal of Advanced and Applied Sciences, 3(3): 28-31.

Vavan Z and Braike S (2015). Data envelopment analysis for weight control strategies. International Journal of Advanced and Applied Sciences, 2(1): 22-24. 